\title{
Synthesis and Characterisation of a Novel Cobalt Carbonyl N-Heterocyclic Carbene Salt. Crystal Structure of $\left[\mathrm{Co}(\mathrm{CO})_{3}(\mathrm{IMes})_{2}\right]^{+}\left[\mathrm{Co}(\mathrm{CO})_{4}\right]^{-}$.
}

\author{
Hendrik van Rensburg, ${ }^{a}$ Robert P. Tooze, ${ }^{a}$ Douglas F. Foster ${ }^{a}$ and \\ Stefanus Otto ${ }^{+\mathbf{b}^{*}}$ \\ ${ }^{a}$ Sasol Technology UK, Purdie Building, North Haugh, St Andrews, U.K., KY16 9ST, \\ ${ }^{\mathrm{b}}$ Sasol Technology Research \& Development, P.O. Box 1, Sasolburg, 1947, South Africa
}

\section{Supporting experimental information}

Dicobalt octacarbonyl, $\mathrm{Co}_{2}(\mathrm{CO})_{8}$ (stabilized with 1-5\% hexanes) and 1,3-bis(2,4,6trimethylphenyl)imidazolium chloride were bought from Strem and used without further purification. Potassium bis(trimethylsilyl)amide, potassium tert-butoxide, anhydrous THF and heptane were bought from Aldrich. Reactions were done using standard Schlenk techniques.

\section{1,3-Bis(2,4,6-trimethylphenyl)imidazol-2-ylidene.}

In a $100 \mathrm{~mL}$ round bottom flask, 1,3-bis(2,4,6-trimethylphenyl)imidazolium chloride $(1.7 \mathrm{~g}, 5.1$ mmol) was stirred in dry THF $(50 \mathrm{~mL})$ for 30 minutes. To this suspension oil-free sodium hydride (147 mg, $6.1 \mathrm{mmol})$ and potassium tert-butoxide $(30 \mathrm{mg}, 0.26 \mathrm{mmol})$ was added and stirred at room temperature for 3-4 h. Hydrogen evolves during the first 1-2 h of the reaction. The reaction mixture was filtered through celite, the filter cake washed with THF ( $2 \times 20 \mathrm{~mL})$ and the solvent removed in vacuo to provide 1,3-bis(2,4,6-trimethylphenyl)imidazol-2-ylidene (930 $\mathrm{mg}, 72 \%)$.

Improved method for preparation of 1,3-bis(2,4,6-trimethylphenyl)imidazol-2-ylidene: A 500 $\mathrm{mL}$ round bottom flask equipped with a stir bar was charged with 1,3-bis(2,4,6trimethylphenyl)imidazolium chloride $(3.4 \mathrm{~g}, 10 \mathrm{mmol})$ and dry THF $(150 \mathrm{~mL})$ and cooled to $0^{\circ} \mathrm{C}$ in an ice bath. While stirring the suspension, potassium bis(trimethylsilyl)amide (2.2 g, $11 \mathrm{mmol})$ was added and the solution was allowed to warm to room temperature over $\sim 2 \mathrm{~h}$ time period. The

${ }^{\dagger}$ Corresponding author. Fax +27-11-5223218; E-mail address: Fanie.Otto@sasol.com 
reaction mixture was filtered through celite and the THF removed in vacuo to provide 1,3bis(2,4,6-trimethylphenyl)imidazol-2-ylidene (2.7 g, 89\%).

${ }^{1} \mathrm{H}$ NMR $\left(d^{8}\right.$-THF, $\left.300 \mathrm{MHz}\right) \delta 2.01$ (s, 2.6- $\left.\mathrm{CH}_{3}, 12 \mathrm{H}\right), 2.30$ (s, 4- $\left.\mathrm{CH}_{3}, 6 \mathrm{H}\right), 6.93$ (s, ArH, 4H), $7.03(\mathrm{~s}, \mathrm{NCH}, 2 \mathrm{H})$

\section{$\left[\mathrm{Co}(\mathrm{CO})_{3}(\mathrm{IMes})_{2}\right]^{+}\left[\mathrm{Co}(\mathrm{CO})_{4}\right]^{-}$}

Anhydrous THF, heptane and cyclohexane were all saturated with $\mathrm{CO}$ by bubbling $\mathrm{CO}$ slowly through theses solvents prior to use. 1,3-Bis(2,4,6-trimethylphenyl)imidazol-2-ylidene (IMes) (420 mg, 1.4mmol) was dissolved in THF $(15 \mathrm{~mL})$. Heptane $(15 \mathrm{~mL})$ was heated to $\left(65^{\circ} \mathrm{C}\right)$ and under a flow of $\mathrm{CO}, \mathrm{Co}_{2}(\mathrm{CO})_{8}(210 \mathrm{mg}, 1.2 \mathrm{mmol} \mathrm{Co})$ was added. The free carbene solution in THF was immediately added and stirred for 30 minutes at $65^{\circ} \mathrm{C}$. The solution was cooled to room temperature and cyclohexane $(2 \mathrm{~mL})$ was added to promote crystallization. It was found that small amounts of precipitate formed at this stage of the procedure and that it was best to filter the solution under inert conditions and discard the precipitate. This solution was kept under a blanket of $\mathrm{CO}$ and after 3 days at room temperature afforded light yellow needles (407 mg). Although the salt was stable in solution under a $\mathrm{CO}$ atmosphere, it was air sensitive and degraded when not stored under $\mathrm{CO}$ atmosphere. Due to this, attempts to obtain accurate reproducible elemental analysis failed. Solution IR indicated that there was still some salt in solution thus explaining the relatively low yield.

${ }^{1} \mathrm{H}$ NMR $\left(d^{8}\right.$-THF, $\left.300 \mathrm{MHz}\right): \delta 2.0\left(\mathrm{~s}, 24 \mathrm{H}, 8 \times \mathrm{CH}_{3}\right), 2.5\left(\mathrm{~s}, 12 \mathrm{H}, 4 \times \mathrm{CH}_{3}\right), 7.0(\mathrm{~s}, 8 \mathrm{H}, 8 \mathrm{x}$ $\mathrm{ArH}), 7.6(\mathrm{~s}, 4 \mathrm{H}, 4 \mathrm{x} \mathrm{NCH}) \mathrm{ppm} ;{ }^{13} \mathrm{C} \mathrm{NMR}\left(d^{8} \mathrm{THF}, 100 \mathrm{MHz}\right): \delta 17.3\left(o-\mathrm{CH}_{3}\right), 20.4\left(p-\mathrm{CH}_{3}\right)$, 128.1 (NCHCHN), 129.4 (Mes C3,5), 135.4 (Mes C4), 135.7 (Mes C2,6), 140.0 (Mes C1), 163.1 $(\mathrm{NCN}), 194.6(\mathrm{CO})$. 


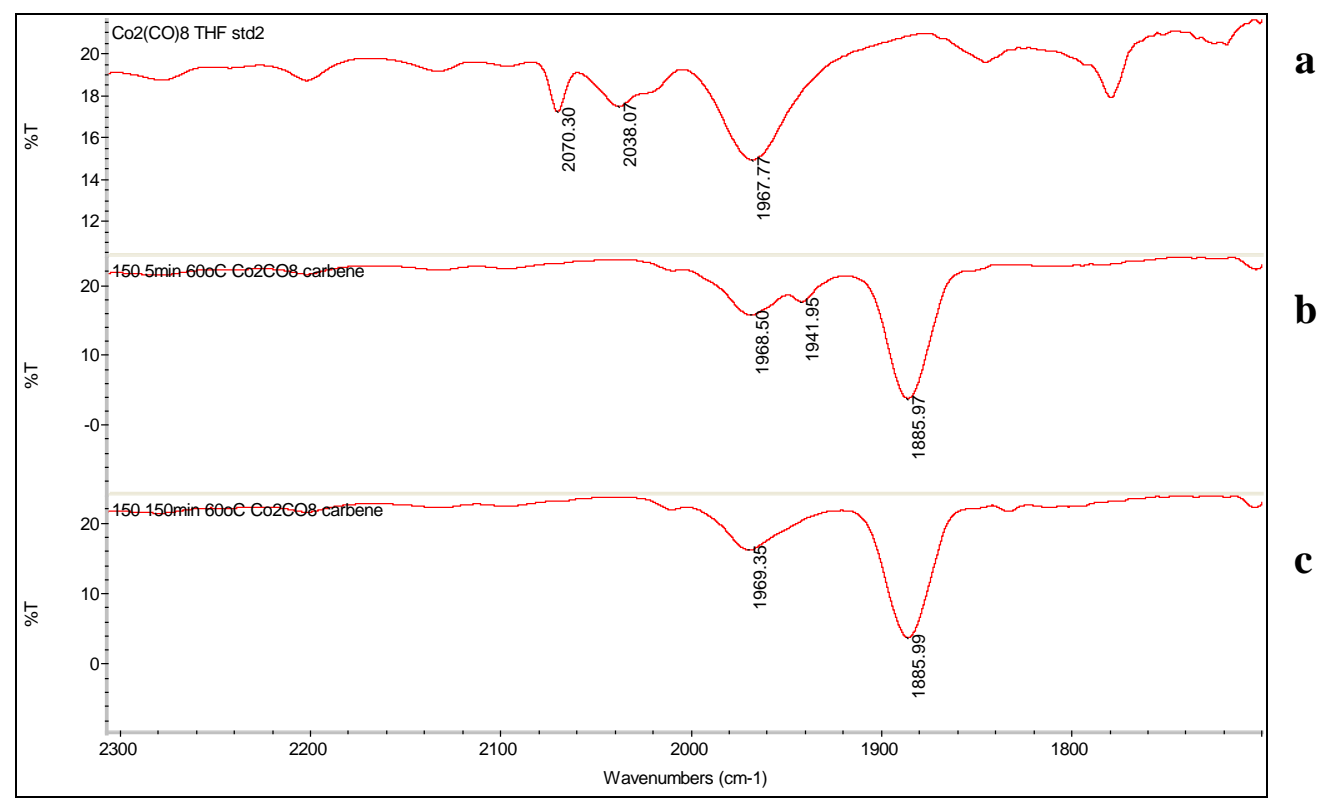

Solution IR: (a) $\mathrm{Co}_{2}(\mathrm{CO})_{8}$ in THF; (b) Addition of a THF solution of $1,3-\mathrm{Bis}(2,4,6-$ trimethylphenyl)imidazol-2-ylidene to solution (a) after 5 minutes at $60^{\circ} \mathrm{C}$ and (c) after 150 minutes at $60^{\circ} \mathrm{C}$. The peak at $1941 \mathrm{~cm}^{-1}$ (vs) in (b) is indicative of a small amount of the dimer, $\left[\mathrm{Co}(\mathrm{CO})_{3}(\mathrm{IMes})\right]_{2}$ while the very strong peak at $1886 \mathrm{~cm}^{-1}\left[\right.$ indicative of $\left.\mathrm{Co}(\mathrm{CO})_{4}^{-}\right]$represents the disproportionate salt $\left[\mathrm{Co}(\mathrm{CO})_{3}(\mathrm{IMes})_{2}\right]^{+}\left[\mathrm{Co}(\mathrm{CO})_{4}\right]^{-}$. 